\title{
USES AND REQUIREMENTS OF ECOLOGICAL NICHE MODELS AND RELATED DISTRIBUTIONAL MODELS
}

\author{
A. TOWNSEND PETERSON \\ Natural History Museum, The University of Kansas, Lawrence, Kansas 66045 USA \\ E-mail town@ku.edu
}

\begin{abstract}
Modeling approaches that relate known occurrences of species to landscape features to discover ecological properties and predict geographic occurrences have seen extensive recent application in ecology, systematics, and conservation. A key component in this process is estimation or characterization of species' distributions in ecological space, which can then be useful in understanding their potential distributions in geographic space. Hence, this process is often termed ecological niche modeling or (less boldly) species distribution modeling. Applications of this approach vary widely in their aims, products, and requirements; this variety is reviewed herein, examples are provided, and differences in data needs and possible interpretations are discussed.
\end{abstract}

Key words. - ecological niche, ecological niche modeling, distribution modeling, geographic distributions.

Recent years have seen impressive growth in use of modeling approaches based on relationships between known occurrences of species and features of the ecological and environmental landscape (Guisan and Zimmermann 2000; Pearson and Dawson 2003; Peterson 2003a; Soberón and Peterson 2004). These models are often termed 'distribution models,' 'climatic envelope models,' or (most generally) 'ecological niche models.' The aim of these studies is generally to reconstruct species' ecological requirements and/or predict geographic distributions of species.

The earliest applications in this realm were undoubtedly those of Joseph Grinnell, in the 1910s and 1920s (Grinnell 1917; Grinnell 1924), who used the spatial distribution of occurrences of species to infer factors limiting their distributions, and laid a firm foundation for subsequent work in this field. The diversity of such applications, however, has now grown considerably. Distributional models and ecological niche models are being used not just to understand species' ecological requirements, but also to understand aspects of biogeography, predict existence of unknown populations and species, identify sites for translocations and reintroductions, plan area selection for conservation, forecast effects of environmental change, etc. (Table 1).
A basic dichotomy that pervades both the list of uses to which these methods are put and even the terminology used to refer to them is that of ecological niche modeling (ENM) versus distributional modeling (DM). A recent paper (Soberón and Peterson 2005) formalized the idea of niche modeling, and clarified the differences between these two views. Niches and distributions of species were visualized as a set of 3 intersecting circles, representing diagrammatically 3 classes of determinants: physical conditions necessary for a species' survival and reproduction ("abiotic niche"; e.g., correct combinations of humidity, temperature, other biophysical variables, substrate types, disturbance regimes), biotic conditions necessary for a species' survival and reproduction ("biotic niche"; e.g., presences of mutualists, absences of diseases and predators), and accessibility (i.e., within the dispersal capabilities of the species, either historically or at present) (Figure 1, top). This latter set of factors is not a niche dimension, but rather is a set of nonecological factors that constrain the species to inhabit less than its full distributional potential, and may indeed not be permanent-as shown in the case of invasive species, dispersal limitations often with time are overcome.

In this framework, where abiotic conditions are appropriate can be compared with the fundamental 


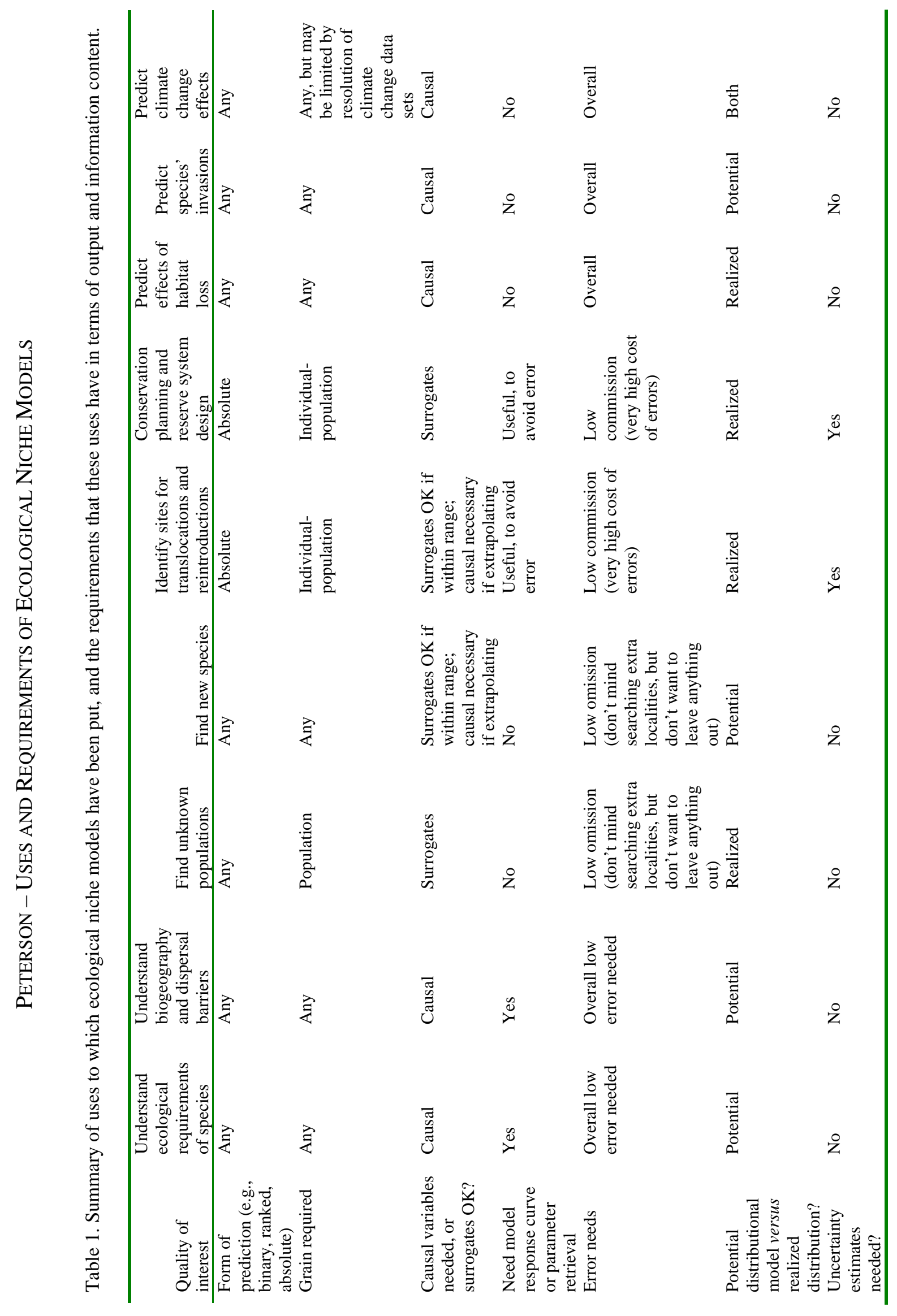


ecological niche of the species, and where abiotic and biotic conditions are fulfilled can be compared with the realized ecological niche of the species (Hutchinson 1957), although Hutchinson focused mostly on competition among the broader suite of potential biotic intereractions; these interactions could potentially be integrated more intimately into the niche modeling framework (Araújo and Guisan 2006). The geographic projection of these conditions (i.e., where both abiotic and biotic requirements are fulfilled) represents the potential distribution of the species (Figure 1, top, blue area) - areas where the species could survive if introduced. Finally, those areas where the potential distribution is accessible to the species is likely to approximate the actual distribution of the species (Figure 1, top, black area). Other authors (Araújo and Guisan 2006) have further distinguished between my 'actual' distribution and the area actually occupied at any point in time, taking into account stochasticity, metapopulation dynamics, etc.

ENM proponents are interested in using distributional information (i.e., known occurrences sampled from the actual distribution) to estimate ecological niches and potential distributions of species, which then provides a means of understanding and anticipating ecological and geographic features of species' distibutional biology (Soberón and Peterson 2005). This approach has the advantage of allowing the effects of the three components listed above to be distinguished, which offers greater interpretability as to causation of phenomena, and permits predictability of phenomena that depend on the differences between components-e.g., the invasive potential of a species depends on the difference between potential and actual distributional areas. This approach, nonetheless, requires additional complexities of interpretation to produce estimates of actual geographic distributions, given that the data on which the niche models are based are not drawn from the entire abiotic niche or even from the potential distribution, but from the actual distributional area (Araújo and Pearson 2005; Pearson and Dawson 2003; Soberón and Peterson 2005; Svenning and Skov 2004).
DM proponents, on the other hand, include effects of abiotic, biotic, and accessibility considerations in their models from the outset. They argue that because distributional information is an expression of a realized ecological niche, as such the realized niche (only) is the target of modeling. As such, DM proponents would often include in the modeling approach independent variables that summarize biotic considerations (e.g., distributions of other species in the region) and that bring in spatial considerations that may be relevant to dispersal ability and accessibility (Leathwick 1998; Latimer et al. 2006). Whereas DM is simpler in producing estimates of species' actual geographic distributions directly, predictivity across scenarios of change is largely lost, and assumptions regarding accessibility of areas may still required (Soberón and Peterson 2005). A further discussion of the differences between ENM and DM is provided below.

This diversity of ideas can place different demands on features of algorithms and approaches used to develop models-and clearly has the potential to lead to debate and perhaps misunderstanding between workers with distinct needs and interests. Nonetheless, contrasts between different conceptualizations of the process (e.g., ENM versus DM) have seen little direct discussion in the literature (Araújo and Guisan 2006; Soberón and Peterson 2005). Such is the purpose of this contribution: to survey the diverse uses to which these approaches have been put, and discuss differences in data needs and interpretation that this diversity demands.

\section{ECOLOGICAL NICHES AND EVOLUTIONARY CONSERVATISM OF NICHES}

In general, readers are referred to recent conceptual reviews (Chase and Leibold 2003; Pulliam 2000; Soberón and Peterson 2005) of relationships among autecology, synecology (i.e., species interactions), and history and accessibility. Once again, this general approach was pioneered by Joseph Grinnell (Grinnell 1917; Grinnell 1924), who was directing detailed series of biological inventories, and was thinking about why species are where they are, and why they are not where they are not. Grinnell's approach, obviously 


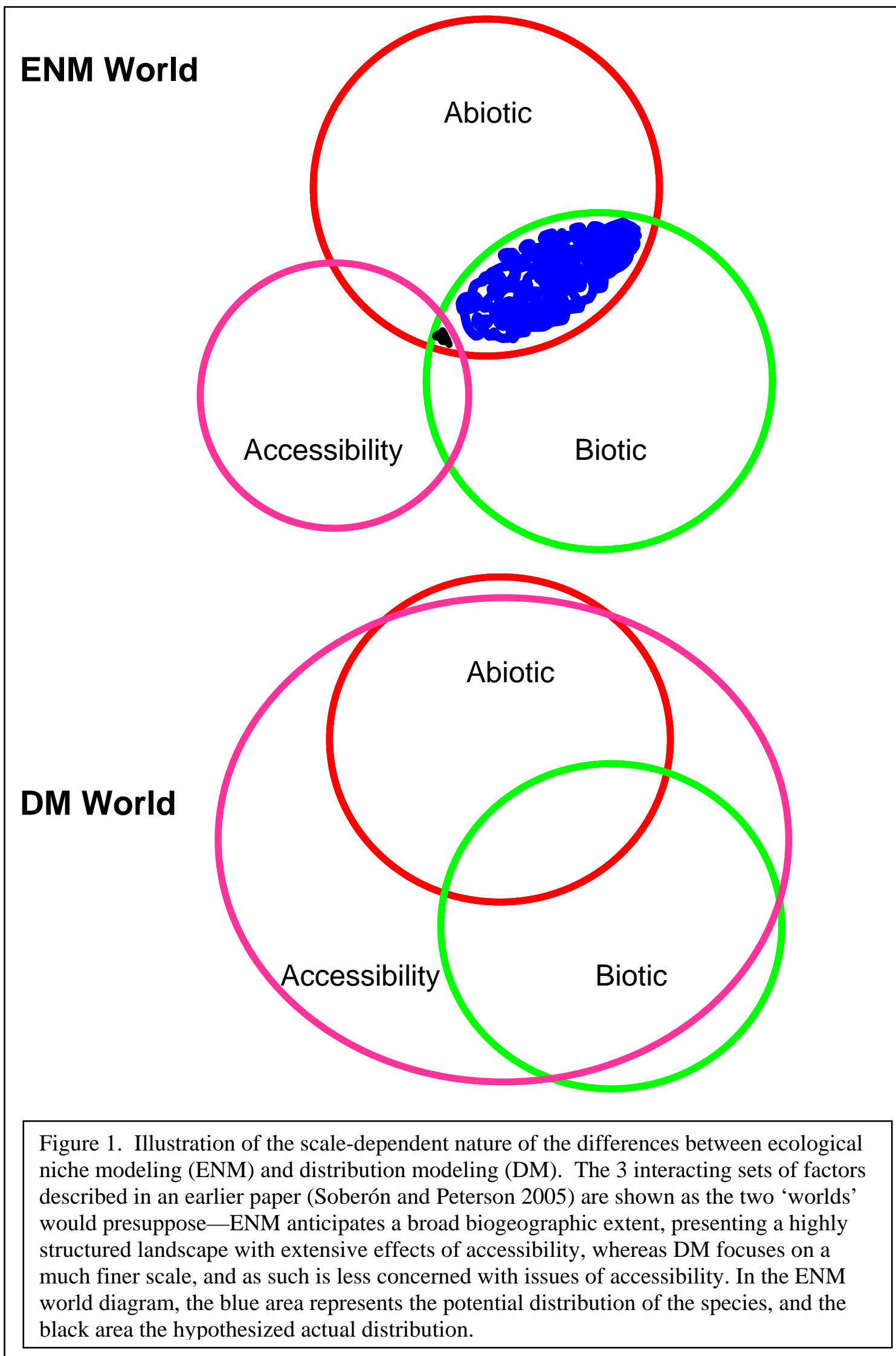




\section{Peterson - Uses And ReQuirements of Ecological Niche Models}

developed without benefit of computer aids for analysis, was to compare environments inside and outside of species' distributions, asking what is different. What is more, Grinnell fully appreciated the independent nature of ecological needs, versus barriers that can interrupt or truncate distributions (Grinnell 1914).

The concept of an ecological niche hasobviously-evolved quite a bit since Grinnell. It was generalized to include biotic as well as abiotic dimensions, evolving to fit into modern community ecology and associated bodies of theory via treatments by several key workers (Hutchinson 1957; MacArthur 1972). Curiously, though, more modern conceptualizations of ecological niches have become successively less useful for geographic, continental-scale views of species' ecological requirements. As such, in ENM applications, a Grinnellian view of niches has generally been adopted-a species' ecological niche can be defined as the set of conditions that permits it to maintain populations without immigrational subsidy.

The idea that ecological niches place constraints on species' geographic distributions hearkens directly back to the very definition of ecological niches by Grinnell himself. However, this 'constraint' requires some clarificationparticularly in light of modern population biological theory regarding metapopulations (Pulliam 1988; Pulliam 2000), in which some suitable areas are expected to be uninhabited, and source-sink dynamics may at times place populations in unsuitable conditions. Certainly, an appreciation of the basic tenets of historical biogeography would suggest that species will not inhabit all areas that meet their niche requirements-rather, barriers to dispersal will often restrict species to a subset of these areas (Peterson 2003a; Peterson et al. 1999). Moreover, the question remains as to whether species are restricted to this particular set of conditions only in the here and now, or are ecological niches evolved characteristics of species that would show inertia (conservatism) over evolutionary time periods? If the latter were the case, ENMs could offer considerable predictive ability for understanding the distribution of that species and perhaps related species.

The roots of the answer to this question came from a paper on beech (Fagus spp.) distributions in
Europe and North America, in which distributions of North American and European beech species were compared with respect to climatic dimensions; the result was that considerable coincidence exists between the two species (Huntley et al. 1989). A more recent paper revisited this idea in a broader suite of species (Peterson et al. 1999), testing coincidence of ecological niche dimensions in 37 sister species pairs separated across the Isthmus of Tehuantepec, in southern Mexico-once again, each species' ecological characteristics were highly predictive of those of its sister species. Significantly, this interpredictivity among sister species broke down when confamilial species pairs were compared (Peterson et al. 1999), suggesting the obviousthat evolutionary conservatism of ecological niches is not absolute, and that they do evolve on broader time scales (Martínez-Meyer 2002; Wiens and Graham 2005).

Further evidence for the stable nature of the constraint on geographic potential by ecological niches can be drawn from two additional types of studies. First, under rare circumstances, data availability permits direct before-and-after characterization of distributions for single species; take, for example, recent papers showing significant predictivity of species' distributions across major events of change, such as the end of the Pleistocene (Martínez-Meyer and Peterson 2006; Martínez-Meyer et al. 2004a). Finally, additional evidence comes from studies of invasive species, in which species are transplanted to a distinct geographic and community context. Although it has been suggested based on theoretical musing and limited laboratory experiments that shifting species' interactions would confound any possible predictivity (in this case in the context of anticipating climate change effects on species' distributions) (Davis et al. 1998), numerous studies have successfully predicted the invasive distributional potential of species based on native-range ecological characteristics (Beerling et al. 1995; Higgins et al. 1999; Honig et al. 1992; Iguchi et al. 2004; Panetta and Dodd 1987; Papes and Peterson 2003; Peterson 2003a; Peterson et al. 2003a; Peterson and Robins 2003; Peterson et al. 2003b; Peterson and Vieglais 2001; Richardson and McMahon 1992; Scott and Panetta 1993; Skov 2000; Sutherst et al. 1999; Zalba et al. 2000). 


\section{Peterson - Uses And Requirements of Ecological Niche Models}

Hence, a diverse and growing body of evidence supports the idea that ecological niche evolution is conservative over short-to-medium periods of evolutionary time, and that models of ecological niches of species can hold significant predictive power for a variety of geographic and ecological phenomena related to biodiversity. Recent theoretical treatments suggest that such should be the case-that, under many circumstances, ecological niche characteristics should not prove particularly labile in their evolution (Brown and Pavlovic 1992; Holt 1996; Holt and Gaines 1992; Holt and Gomulkiewicz 1996; Kawecki 1995). Hence, in practice as well as in theory, ecological niches appear to represent long-term stable constraints on the geographic potential of species.

\section{FUNCTIONALITIES AND POSSIBILITIES}

The following is a set of examples of applications to which ENM approaches have been put. These uses are summarized in Table 1, examples and brief discussion are provided in the text that follows.

\section{- Understand ecological requirements of species}

Too often, elements of biodiversity are so poorly known that a key first step is simply that of understanding the basic ecological dimensions that are relevant to a species' geographic distribution. That is to say, for the vast majority of species, nothing more is known than a few geographic occurrenceseffectively 'dots on maps.' All of the rich detail of natural history, ecology, and behavior can be essentially unknown, but some information can be inferred from ecological niche models. Several examples of this sort of study have been published (Austin and Meyers 1996; Costa et al. 2002; Guisan and Hofer 2003; Hirzel et al. 2002; Luoto et al. 2006; Peterson et al. 2004a; Ron 2005).

\section{- Understand distributions, biogeography and dispersal barriers}

ENM techniques also have considerable potential in identifying geographic phenomena that limit species' distributional potential. As such, ENM provides a tool by which the biogeography of species can be illuminated, providing information about species' distributions that is otherwise basically unavailable. This use of ENM hearkens directly back to Grinnell's original efforts. Examples of this sort of ENM application are numerous (Anderson et al. 2002a; Graham et al. 2004; Manel et al. 1999; Pearce et al. 2001; Robertson et al. 2004; Rojas-Soto et al. 2003;
Skidmore et al. 1996; Svenning and Skov 2004). Further extensions of these applications has addressed the seasonal distributions of migratory species (Joseph 2003; Joseph and Stockwell 2000; MartínezMeyer et al. 2004b; Nakazawa et al. 2004), detection of species' interactions (Anderson et al. 2002b), and fine-scale temporal distributions of ephemeral species (Peterson et al. 2005a).

\section{- Find unknown populations and species}

$\mathrm{ENM}$, in its simplest manifestations, provides a framework by which one can interpolate between known populations of a species to anticipate existence of other, unknown populations. Some species are sufficiently poorly known, or are sufficiently endangered, that encountering new populations can make a clear difference in understanding their distributions and in planning their conservation. Including dimensions of conservatism of ecological niche evolution, this same reasoning can be used to predict the geographic distributions of unknown species closely related to known species. Studies of this sort are growing in number (Bourg et al. 2005; Raxworthy et al. 2003).

\section{- Identify sites for translocations and reintroductions}

Recent discussions have noted that translocations and reintroductions of species closely resemble species' invasions (Bright and Smithson 2001). That is, these deliberate introductions will work only to the extent that the species encounters appropriate conditions in the new landscape, and to the extent that all of the other factors affecting invasion success also coincide (e.g., demographic effects, biotic interactions). Nonetheless, previous studies have focused mainly on factors affecting success of 'establishable' populations (Armstrong and Ewen 2002; Carroll et al. 2003; Howells and Edwards-Jones 1997; Mccallum et al. 1995; Nolet and Baveco 1996; Schadt et al. 2002; South et al. 2000; South et al. 2001; Southgate and Possingham 1995) - few have asked the question of what parts of the landscape are suitable for establishment. As such, ENM provides a framework within which areas may be evaluated for their potential suitability for establishment of populations of species under intensive conservation management. Examples of this sort of ENM application are now beginning to appear (Danks and Klein 2002; Mladenoff et al. 1995; Peterson et al. 2006a).

\section{- Conservation planning and reserve system design}

Many exciting advances have been developed recently for prioritizing areas based on patterns of species' occurrences (Prendergast et al. 1999; Pressey 1994; Williams et al. 1996). These approaches 


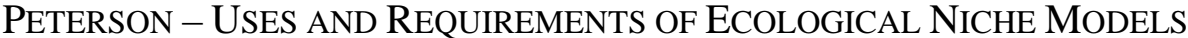

generally focus on the challenge of assembling optimal suites of areas for priority conservation action, and as such represent important new tools in the conservation realm. Nonetheless, the quality of the results of these analyses depends critically on the quality of the distributional information that is fed into them. Given the existence of biases and gaps in the existing sampling, a modeling step to improve the picture of species' distributional areas is warranted, and several efforts have now taken this step (Araújo et al. 2005b; Godown and Peterson 2000; Loiselle et al. 2003; Peterson et al. 2000; Sánchez-Cordero et al. 2005a; Wilson et al. 2005). Further advances in this realm can be derived from use of niche models to identify areas of high probability of population persistence (Araújo et al. 2002) and identifying optimal dispersal corridor locations (Williams et al. 2005); indeed now these place-prioritization algorithms are able to base analyses on probability data (rather than just presence-absence data) (Araújo and Williams 2000; Cabeza et al. 2004; Williams and Araújo 2002). An interesting discussion of issues related to these applications has recently been published (Rondinini et al. 2006).

- Predict effects of habitat loss

Species appear often to obey different suites of environmental factors at different spatial scales (Ortega-Huerta and Peterson 2003). That is to say, they may seek optimal suites of climatic conditions at relatively coarse conditions, but may respond to land cover type or soil type at finer scales (Coudin et al. 2006; Midgley et al. 2003), and to food distributions at micro-scales. As such, at times, investigators may be able to model species' niches at coarse scales, but then use additional information (e.g., land cover type) to refine the model's predictions. To the extent that species' responses to these finer-scale phenomena remain constant over time, then these models can be used to anticipate future distributional potential in the face of changing patterns of habitat distribution and land use. Explorations of applying these ideas in an ENM framework have been developed and applied now in several situations (Peterson et al. 2006b; Sánchez-Cordero et al. 2005a; Sánchez-Cordero et al. 2005b; Thuiller et al. 2004).

\section{- Predict potential for species' invasions}

This ENM application is perhaps that which has seen the most intensive exploration by many laboratories, with examples developed for numerous taxa worldwide. Here, the idea is that-given apparently widespread evolutionary conservatism in ecological niche characteristics-species will often 'obey' the same set of ecological rules on invaded distributional areas as they do on their native distributional areas. As such, the geographic potential of invasive species is often quite predictable, based on their geographic and ecological distributions on their native distributional areas (Beerling et al. 1995; Higgins et al. 1999; Hinojosa-Díaz et al. 2005; Hoffmann 2001; Honig et al. 1992; Iguchi et al. 2004; Panetta and Dodd 1987; Papes and Peterson 2003; Peterson 2003a; Peterson et al. 2003a; Peterson and Robins 2003; Peterson et al. 2003b; Peterson and Vieglais 2001; Podger et al. 1990; Richardson and McMahon 1992; Robertson et al. 2004; Sindel and Michael 1992; Skov 2000; Sutherst et al. 1999; Welk et al. 2002; Zalba et al. 2000), although the factors that make a species invasive are clearly more complex than just niche considerations (Thuiller et al. 2005b).

\section{- Predict climate change effects}

To the extent that species' ecological niches remain fairly constant, and do not evolve to meet changing conditions, it is possible to project present-day niche models onto future conditions of climate, as represented in large-scale climate models (Flato et al. 1999; McFarlane et al. 1992; Pope et al. 2002). These projections, under assumptions made fairly explicit, provide hypotheses of species' potential geographic distributions and how they will change over the next few decades of evolving world climates, and this field has now seen extensive activity (Araújo et al. 2005a; Araújo et al. 2006; Berry et al. 2002; Carey and Brown 1994; Erasmus et al. 2002; Gottfried et al. 1999; Huntley et al. 1995; Kadmon and Heller 1998; Malanson et al. 1992; Pearson and Dawson 2003; Pearson et al. 2002; Peterson 2003b; Peterson et al. 2004b; Peterson et al. 2002; Peterson et al. 2001; Peterson and Shaw 2003; Peterson et al. 2005b; Porter et al. 2000; Price 2000; Roura-Pascual et al. 2005; Sykes et al. 1996; Thuiller et al. 2005a), including retro-projections aimed at reconstructing distributions in the Pleistocene (Hilbert et al. 2004; Hugall et al. 2002; Martínez-Meyer and Peterson 2006; MartínezMeyer et al. 2004a). The complexities of these projections, however, are only beginning to be appreciated, given species' responses to other factors such as atmospheric gas composition (Thuiller et al. 2006).

\section{DISTRIBUTIONAL MODELING}

Distribution modeling, as it is usually depicted by its proponents, appears to constitute an effort not to overinterpret conceptually the models resulting in what would otherwise be ENM. That is, the usual argument goes, because the occurrence data on which models are trained are sampled from the actual distribution of the species, it is improbable that the model can say anything about the potential distribution or fundamental 


\section{Peterson - Uses And ReQuirements of Ecological Niche Models}

ecological niche of the species. While these arguments have some merit if interactions were to occur universally and in ecological dimensions (rather than in geographic dimensions-'who gets there first'), I argue that such situations are rare, although this is clearly a topic for future detailed analyses. That is, I argue that many species interactions take place in geographic space, and that they are far from universal: in this way, ecological potential of species is manifest in some portion of the range, and good (dense, representative) sampling will usually reveal that potential (Araújo and Guisan 2006): a worked example is provided in a recent publication (Anderson et al. 2002b), and the theoretical issues have also been reviewed recently (Soberón and Peterson 2005).

Another interpretation of the ENM-DM debate focuses on the scale of the inquiry (see Figure 1). Here, whereas ENM proponents would anticipate a full-species'-range scale for a study, DM proponents may be willing to examine a much smaller portion of species' distributions. As such, accessibility considerations become unimportant in DM (as the entire study area tends to be available to the species), whereas ENM-which is often developed at broader scales (such as that of an entire species' distribution) must take them into account more explicitly.

$\mathrm{DM}$, given that it is able to rely on assumptions such as that dispersal limitation is relatively immaterial in sculpting species' distributions, is often able to produce more accurate local predictions within regions. However, DM results are often limited by spatial references in environmental data sets used to build models, and the limited spatial scales of inquiry may often provide incomplete characterization of niches of species. ENM, on the other hand, uses the conservative nature of ecological niche characteristics of species to open additional suites of predictive capabilities, and provides a clearer interpretation of causal forces affecting species' distributions. However, ENM models may be difficult to test and validate because special assumptions are required to turn potential distribution estimates into actual distribution estimates.

\section{DISCUSSION AND CONCLUSIONS}

The diversity of applications discussed above suggests that important methodological requirements may also differ among applications. That is, different applications may require distinct assumptions and interpretations to make possible a particular result. Table 1 details a number of considerations that may be relevant in this respect.

These points are relevant also to the challenge of choosing among the many options for creating ecological niche models in the first place. The community of investigators that use these approaches use many different inferential techniques. These techniques include very simple range-rule approaches that detect limits along independent environmental axes, multivariate statistical approaches that fit response curves in environmental space, and evolutionary computing approaches that explore solution space randomly to produce 'best' solutions to the challenge. These different techniques interact with the uses listed in Table 1 as well-some techniques may be better suited to some uses.

Qualities of interest regarding uses and a brief discussion of their interaction with techniques and uses, are as follows:

- Form of prediction (e.g., binary, ranked, absolute) Some uses (e.g., identification of sites for translocations and reintroductions, conservation planning and reserve system design) require an absolute, rather than a relative, answer to the question of suitability. That is to say, it does no good to reintroduce a species to the best site in a landscape if that site is not highly suitable for the species to become established. These uses will thus require inferential approaches that have some mode of calibration to indicate which sites are equally suitable as those where the species does maintain or has maintained populations.

- Grain required - Grain required for usable predictions varies from a grain relevant to individual or at least population distributions (e.g., identification of sites for translocations and reintroductions) up to broader-scale views (e.g., prediction of climate change effects). Although the details depend on the extent of the area under consideration, this factor will clearly demand that inferential algorithms be able to deal with large data sets in developing models.

- Causal variables needed, or surrogates OK? - The issue of what is a causal variable is not simple. 


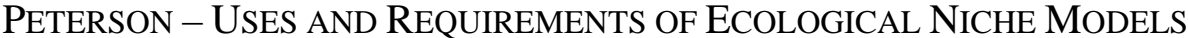

Causation is not a yes-no issue, but rather is an issue of relative immediacy. For example, humidity may be directly related to survival, but the most proximate manifestation of 'humidity' may be whether a species' eggs desiccate before they can hatch. Nonetheless, clearly, some variables are likely to be surrogates for 'real' causal variables. Similarly, many models use elevation as an independent variable-elevation nonetheless is really an excellent surrogate for temperature, but cannot be used in place of temperature, e.g., when climates change, because elevation would have a changing meaning in different climate regimes. The different uses break down about evenly as to whether surrogates are acceptable, or whether causal variables are needed (Table 1 ).

- Need model response curve or parameter retrieval Some modeling approaches (e.g., multivariate statistical approaches) are able to reconstruct the roles of individual independent variables in model predictions, whereas others (e.g., evolutionary computing approaches) must reconstruct this information in a more post hoc manner. Although both approaches can potentially 'get at' the issue of the shape of the response curve to particular environmental variables, the former are clearly more convenient.

- Error needs - Two general types of error are possible in modeling species' niches and distributions_omission (leaving out of the prediction areas that are within the species' ecological potential), and commission (including in the prediction areas outside of the species' ecological potential). Different uses of modeling emphasize different error components as more or less important-for example, understanding ecological requirements of species would emphasize minimizing both error components simultaneously, whereas identification of sites for reintroductions would require low commission error (high cost of error as to which sites are suitable).

- Potential distributional model versus realized distribution? - Several of the uses detailed in Table 1 are clearly functions of potential distributions, rather than actual distributions of species. For example, all applications to predicting species' invasions would perforce have to be based on estimates of potential distributions, whereas other applications (e.g., conservation planning and reserve design) would either demand actual distributional estimates or potential distributional estimates refined by specific assumptions regarding interactions with other species and dispersal abilities.
- Uncertainty estimates needed? - Finally, because of high costs of being wrong in bases for decisions, applications such as identification of sites for translocations and reintroductions and conservation planning and reserve system design require careful estimates of uncertainty associated with predictions. Such estimates are most easily drawn from multivariate statistical approaches, although they are possible using other approaches as well.

In sum, the world of modeling ecological and geographic distributions of species is simultaneously complex (see the preceding list of considerations in choosing modeling methods) and promising (see the exciting list of uses farther above). This field is clearly just recently achieving much of the breadth of its potential, and as a consequence is seeing increasing interest and application.

This contribution is intended principally as a platform for discussion. That is, much of what is said regarding particular applications and uses and their requirements for inferential algorithms is opinion, and is intended to spark discussion and debate, laying out one point of view. My hope is that this contribution can serve to initiate such a debate, and by this means improve the conceptual platform on which an even-more-vibrant field of inquiry can be based.

\section{ACKNOWLEDGMENTS}

This work was supported generously by the National Center for Ecological Analysis and Synthesis, University of California, Santa Barbara, and benefitted enormously from discussions and debates with members of the Working Group on Predicting Species' Distributions, particularly with Simon Ferrier. Guy Midgely and Miguel B. Araújo provided very helpful comments on an earlier version of this paper.

\section{REFERENCES}

Anderson, R. P., M. Gómez-Laverde, and A. T. Peterson. 2002a. Geographical distributions of spiny pocket mice in South America: Insights from predictive models. Global Ecology and Biogeography 11:131-141.

Anderson, R. P., A. T. Peterson, and M. GómezLaverde. 2002b. Using niche-based GIS modeling to test geographic predictions of competitive exclusion and competitive release in South American pocket mice. Oikos 93:3-16. 


\section{Peterson - Uses And ReQuirements of Ecological Niche Models}

Araújo, M. B., and A. Guisan. 2006. Five (or so) challenges for species distribution modelling. Journal of Biogeography 33:1677-1688.

Araújo, M. B., and R. G. Pearson. 2005. Equilibrium of species' distributions with climate. Ecography 28:693-695.

Araújo, M. B., R. G. Pearson, W. Thuiller, and M. Erhard. 2005a. Validation of species-climate impact models under climate change. Global Change Biology 11:1504-1513.

Araújo, M. B., W. Thuiller, and R. G. Pearson. 2006. Climate warming and the decline of amphibians and reptiles in Europe. Journal of Biogeography 33:17121728.

Araújo, M. B., W. Thuiller, P. H. Williams, and I. Reginster. 2005b. Downscaling European species atlas distributions to a finer resolution: Implications for conservation planning. Global Ecology and Biogeography 14:17-30.

Araújo, M. B., and P. H. Williams. 2000. Selected areas for species persistence using occurrence data. Biological Conservation 96:331-345.

Araújo, M. B., P. H. Williams, and R. J. Fuller. 2002. Dynamics of extinction and the selection of nature reserves. Proceedings of the Royal Society of London B 269:1971-1980.

Armstrong, D. P., and J. G. Ewen. 2002. Dynamics and viability of a New Zealand robin population reintroduced to regenerating fragmented habitat. Conservation Biology 16:1074-1085.

Austin, M. P., and J. A. Meyers. 1996. Current approaches to modelling the environmental niche of eucalypts: Implications for management of forest biodiversity. Forest Ecology and Management 85:95106.

Beerling, D. J., B. Huntley, and J. P. Bailey. 1995. Climate and the distribution of Fallopia japonica: Use of an introduced species to test the predictive capacity of response surfaces. Journal of Vegetation Science 6:269-282.

Berry, P. M., T. P. Dawson, P. A. Harrison, and R. G. Pearson. 2002. Modelling potential impacts of climate change on the bioclimatic envelope of species in Britain and Ireland. Global Ecology and Biogeography 11:453-462.

Bourg, N. A., W. J. McShea, and D. E. Gill. 2005. Putting a CART before the search: Successful habitat prediction for a rare forest herb. Ecology 86:27932804.

Bright, P. W., and T. J. Smithson. 2001. Biological invasions provide a framework for reintroductions: Selecting areas in England for pine marten releases. Biodiversity and Conservation 10:1247-1265.

Brown, J. S., and N. B. Pavlovic. 1992. Evolution in heterogeneous environments: Effects of migration on habitat specialization. Evolutionary Ecology 6:360382.

Cabeza, M., M. B. Araújo, R. J. Wilson, C. D. Thomas, M. J. R. Cowley, and A. Moilanen. 2004.

Combining probabilities of occurrence with spatial reserve design. Journal of Applied Ecology 41:252262.

Carey, P. D., and N. J. Brown. 1994. The use of GIS to identify sites that will become suitable for a rare orchid, Himantoglossum hircinum L., in a future changed climate. Biodiversity Letters 2:117-123.

Carroll, C., M. K. Phillips, N. H. Schumaker, and D. W. Smith. 2003. Impacts of landscape change on wolf restoration success: Planning a reintroduction program based on static and dynamic spatial models. Conservation Biology 17:536-548.

Chase, J. M., and M. A. Leibold. 2003. Ecological Niches: Linking Classical and Contemporary Approaches. University of Chicago Press, Chicago.

Costa, J., A. T. Peterson, and C. B. Beard. 2002. Ecological niche modeling and differentiation of populations of Triatoma brasiliensis Neiva, 1911, the most important Chagas disease vector in northeastern Brazil (Hemiptera, Reduviidae, Triatominae). American Journal of Tropical Medicine \& Hygiene 67:516-520.

Coudin, C., J. C. Gégout, C. Piedallu, and J. C. Rameau. 2006. Soil nutritional factors improve plant species distribution models: An illustration with Acer campestre (L.) in France. Journal of Biogeography, in press.

Danks, F. S., and D. R. Klein. 2002. Using GIS to predict potential wildlife habitat: a case study of muskoxen in northern Alaska. International Journal of Remote Sensing 23:4611-4632.

Davis, A. J., L. S. Jenkinson, J. H. Lawton, B. Shorrocks, and S. Wood. 1998. Making mistakes when predicting shifts in species range in response to global warming. Nature 391:783-786.

Erasmus, B. F. N., A. S. Van Jaarsveld, S. L. Chown, M. Kshatriya, and K. J. Wessels. 2002. Vulnerability of South African animal taxa to climate change. Global Change Biology 8:679-693.

Flato, G. M., G. J. Boer, W. G. Lee, N. A. McFarlane, D. Ramsden, M. C. Reader, and A. J. Weaver. 1999. The Canadian Center for Climate Modelling and Analysis Global Coupled Model and its climate. Climate Dynamics 16:451-467.

Godown, M. E., and A. T. Peterson. 2000. Preliminary distributional analysis of U.S. endangered bird species. Biodiversity and Conservation 9:1313-1322.

Gottfried, M., H. Pauli, K. Reiter, and G. Grabherr. 1999. A fine-scaled predictive model for changes in species distribution patterns of high mountain plants induced by climate warming. Diversity and Distributions 5:241-251. 


\section{Peterson - Uses AND ReQUiREMENTS OF ECOLOGICAL Niche Models}

Graham, C. H., S. R. Ron, J. C. Santos, C. J. Schneider, and C. Moritz. 2004. Integrating phylogenetics and environmental niche models to explore speciation mechanisms in dendrobatid frogs. Evolution 58:17811793.

Grinnell, J. 1914. Barriers to distribution as regards birds and mammals. American Naturalist 48:248-254.

Grinnell, J. 1917. Field tests of theories concerning distributional control. American Naturalist 51:115128.

Grinnell, J. 1924. Geography and evolution. Ecology 5:225-229.

Guisan, A., and U. Hofer. 2003. Predicting reptile distributions at the mesoscale: Relation to climate and topography. Journal of Biogeography 30:1233-1243.

Guisan, A., and N. E. Zimmermann. 2000. Predictive habitat distribution models in ecology. Ecological Modelling 135:147-186.

Higgins, S. I., D. M. Richardson, R. M. Cowling, and T. H. Trinder-Smith. 1999. Predicting the landscapescale distribution of alien plants and their threat to plant diversity. Conservation Biology 13:303-313.

Hilbert, D. W., M. Bradford, T. Parker, and D. A. Westcott. 2004. Golden bowerbird (Prionodura newtonia) habitat in past, present and future climates: predicted extinction of a vertebrate in tropical highlands due to global warming. Biological Conservation 116:367-377.

Hinojosa-Díaz, I. A., O. Yáñez-Ordóñez, G. Chen, and A. T. Peterson. 2005. The North American invasion of the Giant Resin Bee (Hymenoptera: Megachilidae). Journal of Hymenoptera Research 14:69-77.

Hirzel, A. H., J. Hausser, D. Chessel, and N. Perrin. 2002. Ecological-niche factor analysis: How to compute habitat-suitability maps without absence data? Ecology 83:2027-2036.

Hoffmann, M. H. 2001. The distribution of Senecio vulgaris: Capacity of climatic range models for predicting adventitious ranges. Flora 196/5:395-403.

Holt, R. D. 1996. Adaptive evolution in source-sink environments: Direct and indirect effects of densitydependence on niche evolution. Oikos 75:182-192.

Holt, R. D., and M. S. Gaines. 1992. Analysis of adaptation in heterogeneous landscapes: Implications for the evolution of fundamental niches. Evolutionary Ecology 6:433-447.

Holt, R. D., and R. Gomulkiewicz. 1996. The evolution of species' niches: A population dynamic perspective. Pp. 25-50 in H. G. Othmer, F. R. Adler, M. A. Lewis and J. C. Dallon, eds. Case Studies in Mathematical Modeling: Ecology, Physiology and Cell Biology. Prentice-Hall, Saddle River, N.J.

Honig, M. A., R. M. Cowling, and D. M. Richardson. 1992. The invasive potential of Australian banksias in South-African fynbos--A comparison of the reproductive potential of Banksia ericifolia and
Leucadendron laureolum. Australian Journal of Ecology 17:305-314.

Howells, O., and G. Edwards-Jones. 1997. A feasibility study of reintroducing wild boar Sus scrofa to Scotland: Are existing woodlands large enough to support minimum viable populations. Biological Conservation 81:77-89.

Hugall, A., C. Moritz, A. Moussalli, and J. Stanisic. 2002. Reconciling paleodistribution models and comparative phylogeography in the Wet Tropics rainforest land snail Gnarosophia bellendenkerensis (Brazier 1875). Proceedings of the National Academy of Sciences USA 99:6112-6117.

Huntley, B., P. J. Bartlein, and I. C. Prentice. 1989. Climatic control of the distribution and abundance of Beech (Fagus L.) in Europe and North America. Journal of Biogeography 16:551-560.

Huntley, B., P. M. Berry, W. Cramer, and A. P. McDonald. 1995. Modelling present and potential future ranges of some European higher plants using climate response surfaces. Journal of Biogeography 22:967-1001.

Hutchinson, G. E. 1957. Concluding remarks. Cold Spring Harbor Symposia on Quantitative Biology 22:415-427.

Iguchi, K., K. Matsuura, K. McNyset, A. T. Peterson, R. Scachetti-Pereira, K. A. Powers, D. A. Vieglais, E. O. Wiley, and T. Yodo. 2004. Predicting invasions of North American basses in Japan using native range data and a genetic algorithm. Transactions of the American Fisheries Society 133:845-854.

Joseph, L. 2003. Predicting distributions of South American migrant birds in fragmented environments: A possible approach based on climate. Pp. 263-284 in G. A. Bradshaw and P. Marquet, eds. How Landscapes Change: Human Disturbance and Ecosystem Fragmentation in the Americas. SpringerVerlag, Inc., Berlin.

Joseph, L., and D. R. B. Stockwell. 2000. Temperature-based models of the migration of Swainson's Flycatcher (Myiarchus swainsoni) across South America: A new use for museum specimens of migratory birds. Proceedings of the Academy of Natural Sciences of Philadelphia 150:293-300.

Kadmon, R., and J. Heller. 1998. Modelling faunal responses to climatic gradients with GIS: Land snails as a case study. Journal of Biogeography 25:527-539.

Kawecki, T. J. 1995. Demography of source-sink populations and the evolution of ecological niches. Evolutionary Ecology 9:38-44.

Latimer, A. M., S. Wu, A. E. Gelfand, and J. A. Silander Jr. 2006. Building statistical models to analyze species distributions. Ecological Applications 16:33-50.

Loiselle, B. A., C. A. Howell, C. H. Graham, J. M. Goerck, T. M. Brooks, K. G. Smith, and P. H. 


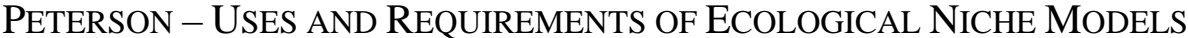

Williams. 2003. Avoiding pitfalls of using species distribution models in conservation planning. Conservation Biology 17:1591-1600.

Luoto, M., R. K. Heikkinen, J. Pöyry, and K. Saarinen. 2006. Determinants of biogeographical distribution of butterflies in boreal regions. Journal of Biogeography 33:1764-1778.

MacArthur, R. 1972. Geographical Ecology. Princeton University Press, Princeton, N.J.

Malanson, G. P., W. E. Westman, and Y.-L. Yan. 1992. Realized versus fundamental niche functions in a model of chaparral response to climatic change. Ecological Modelling 64:261-277.

Manel, S., J. M. Dias, S. T. Buckton, and S. J. Ormerod. 1999. Alternative methods for predicting species distribution: An illustration with Himalayan river birds. Journal of Applied Ecology 36:734-747.

Martínez-Meyer, E. 2002. Evolutionary Trends in Ecological Niches of Species. Ph.D. thesis, Department of Geography, University of Kansas, Lawrence, Kansas.

Martínez-Meyer, E., and A. T. Peterson. 2006. Conservatism of ecological niche characteristics in North American plant species over the Pleistocene-toRecent transition. Journal of Biogeography 33:17791789.

Martínez-Meyer, E., A. T. Peterson, and W. W. Hargrove. 2004a. Ecological niches as stable distributional constraints on mammal species, with implications for Pleistocene extinctions and climate change projections for biodiversity. Global Ecology and Biogeography 13:305-314.

Martínez-Meyer, E., A. T. Peterson, and A. G. NavarroSigüenza. 2004b. Evolution of seasonal ecological niches in the Passerina buntings (Aves:

Cardinalidae). Proceedings of the Royal Society B 271:1151-1157.

McCallum, H., P. Timmers, and S. Hoyle. 1995. Modeling the impact of predation on reintroductions of Bridled Nailtail Wallabies. Wildlife Research 22:163-171.

McFarlane, N. A., G. J. Boer, J.-P. Blanchet, and M. Lazare. 1992. The Canadian Climate Centre secondgeneration general circulation model and its equilibrium climate. Journal of Climate 5:1013-1044.

Midgley, G. F., L. Hannah, D. Millar, W. Thuiller, and A. Booth. 2003. Developing regional and specieslevel assessments of climate change impacts on biodiversity in the Cape Floristic Region. Biological Conservation 112:87-97.

Mladenoff, D. J., T. A. Sickley, R. G. Haight, and A. P. Wydeven. 1995. A regional landscape analysis and prediction of favorable gray wolf habitat in the northern Great Lakes region. Conservation Biology 9:279-294.
Nakazawa, Y., A. T. Peterson, E. Martínez-Meyer, and A. G. Navarro-Sigüenza. 2004. Seasonal niches of Nearctic-Neotropical migratory birds: Implications for the evolution of migration. Auk 121:610-618.

Nolet, B. A., and J. M. Baveco. 1996. Development and viability of a translocated beaver Castor fiber population in the Netherlands. Biological Conservation 75:125-137.

Ortega-Huerta, M. A., and A. T. Peterson. 2003. Effects of geographic scale on analyzing associations between regional habitats and distribution patterns of Mexican birds. Anales del Instituto de Biologia, U.N.A.M. 74:203-210.

Panetta, F. D., and J. Dodd. 1987. Bioclimatic prediction of the potential distribution of skeleton weed Chondrilla juncea L. in Western Australia. Journal of the Australian Institute of Agricultural Science 53:11-16.

Papes, M., and A. T. Peterson. 2003. Predicting the potential invasive distribution for Eupatorium adenophorum Spreng. in China. Journal of Wuhan Botanical Research 21:137-142.

Pearce, J., S. Ferrier, and D. Scotts. 2001. An evaluation of the predictive performance of distributional models for flora and fauna in north-east New South Wales. Journal of Environmental Management 62:171-184.

Pearson, R. G., and T. P. Dawson. 2003. Predicting the impacts of climate change on the distribution of species: Are bioclimate envelope models useful? Global Ecology and Biogeography 12:361-371.

Pearson, R. G., T. P. Dawson, P. M. Berry, and P. A. Harrison. 2002. SPECIES: A spatial evaluation of climate impact on the envelope of species. Ecological Modelling 154:289-300.

Peterson, A. T. 2003a. Predicting the geography of species' invasions via ecological niche modeling. Quarterly Review of Biology 78:419-433.

Peterson, A. T. 2003b. Projected climate change effects on Rocky Mountain and Great Plains birds: Generalities of biodiversity consequences. Global Change Biology 9:647-655.

Peterson, A. T., J. T. Bauer, and J. N. Mills. 2004a. Ecological and geographic distribution of filovirus disease. Emerging Infectious Diseases 10:40-47.

Peterson, A. T., S. L. Egbert, V. Sánchez-Cordero, and K. P. Price. 2000. Geographic analysis of conservation priority: Endemic birds and mammals in Veracruz, Mexico. Biological Conservation 93:85-94.

Peterson, A. T., C. Martínez-Campos, Y. Nakazawa, and E. Martínez-Meyer. 2005a. Time-specific ecological niche modeling predicts spatial dynamics of vector insects and human dengue cases. Transactions of the Royal Society of Tropical Medicine and Hygiene 99:647-655. 


\section{Peterson - Uses ANd ReQuiRements of ECOlOGiCAl Niche Models}

Peterson, A. T., E. Martínez-Meyer, C. GonzálezSalazar, and P. Hall. 2004b. Modeled climate change effects on distributions of Canadian butterfly species. Canadian Journal of Zoology 82:851-858.

Peterson, A. T., E. Martínez-Meyer, J. Servin, and L. F. Kiff. 2006a. Ecological niche modelling and strategizing for species reintroductions. Oryx in press

Peterson, A. T., M. A. Ortega-Huerta, J. Bartley, V. Sanchez-Cordero, J. Soberon, R. H. Buddemeier, and D. R. B. Stockwell. 2002. Future projections for Mexican faunas under global climate change scenarios. Nature 416:626-629.

Peterson, A. T., M. Papes, and D. A. Kluza. 2003a. Predicting the potential invasive distributions of four alien plant species in North America. Weed Science 51:863-868.

Peterson, A. T., and C. R. Robins. 2003. Using ecological-niche modeling to predict Barred Owl invasions with implications for Spotted Owl conservation. Conservation Biology 17:1161-1165.

Peterson, A. T., V. Sánchez-Cordero, E. MartínezMeyer, and A. G. Navarro-Sigüenza. 2006b. Tracking population extirpations via melding ecological niche modeling with land-cover information. Ecological Modelling 195:229-236.

Peterson, A. T., V. Sanchez-Cordero, J. Soberon, J. Bartley, R. H. Buddemeier, and A. G. NavarroSiguenza. 2001. Effects of global climate change on geographic distributions of Mexican Cracidae. Ecological Modelling 144:21-30.

Peterson, A. T., R. Scachetti-Pereira, and D. A. Kluza. 2003b. Assessment of invasive potential of Homalodisca coagulata in western North America and South America. Biota Neotropica 3:Online journal.

Peterson, A. T., and J. J. Shaw. 2003. Lutzomyia vectors for cutaneous leishmaniasis in southern Brazil: Ecological niche models, predicted geographic distributions, and climate change effects. International Journal of Parasitology 33:919-931.

Peterson, A. T., J. Soberón, and V. Sánchez-Cordero. 1999. Conservatism of ecological niches in evolutionary time. Science 285:1265-1267.

Peterson, A. T., H. Tian, E. Martínez-Meyer, J. Soberón, V. Sánchez-Cordero, and B. Huntley. 2005b. Modeling distributional shifts of individual species and biomes. Pp. 211-228 in T. E. Lovejoy and L. Hannah, eds. Climate Change and Biodiversity. Yale University Press, New Haven, Conn.

Peterson, A. T., and D. A. Vieglais. 2001. Predicting species invasions using ecological niche modeling. BioScience 51:363-371.

Podger, F. D., D. C. Mummery, C. R. Palzer, and M. J. Brown. 1990. Bioclimatic analysis of the distribution of damage to native plants in Tasmania by Phytophthora cinnamomi. Australian Journal of Ecology 15:281-290.
Pope, V. D., M. L. Gallani, V. J. Rowntree, and R. A. Stratton. 2002. The impact of new physical parametrizations in the Hadley Centre climate model HadAM3. Hadley Centre for Climate Prediction and Research, Bracknell, Berks, UK.

Porter, W. P., S. Budaraju, W. E. Stewart, and N. Ramankutty. 2000. Calculating climate effects on birds and mammals: Impacts on biodiversity, conservation, population parameters, and global community structure. American Zoologist 40:597630.

Prendergast, J. R., R. M. Quinn, and J. H. Lawton. 1999. The gaps between theory and practice in selecting nature reserves. Conservation Biology 13:484-492.

Pressey, R. 1994. Ad hoc reservations: Forward or backward steps in developing representative reserve systems. Conservation Biology 8:662-668.

Price, J. 2000. Modeling the potential impacts of climate change on the summer distributions of Massachusetts passerines. Bird Observer 28:224-230.

Pulliam, H. R. 1988. Sources, sinks and population regulation. American Naturalist 132:652-661.

Pulliam, H. R. 2000. On the relationship between niche and distribution. Ecology Letters 3:349.

Raxworthy, C. J., E. Martínez-Meyer, N. Horning, R. A. Nussbaum, G. E. Schneider, M. A. Ortega-Huerta, and A. T. Peterson. 2003. Predicting distributions of known and unknown reptile species in Madagascar. Nature 426:837-841.

Richardson, D. M., and J. P. McMahon. 1992. A bioclimatic analysis of Eucalyptus nintens to identify potential planting regions in Southern Africa. South African Journal of Science 88:380-387.

Robertson, M. P., M. H. Villet, and A. R. Palmer. 2004. A fuzzy classification technique for predicting species' distributions: Applications using invasive alien plants and indigenous insects. Diversity and Distributions 10:461-474.

Rojas-Soto, O. R., O. Alcantara-Ayala, and A. G. Navarro. 2003. Regionalization of the avifauna of the Baja California Peninsula, Mexico: A parsimony analysis of endemicity and distributional modelling approach. Journal of Biogeography 30:449-461.

Ron, S. R. 2005. Predicting the distribution of the amphibian pathogen Batrachochytrium dendrobatidis in the New World. Biotropica 37:209-221.

Roura-Pascual, N., A. Suarez, C. Gómez, P. Pons, Y. Touyama, A. L. Wild, and A. T. Peterson. 2005. Geographic potential of Argentine ants (Linepithema humile Mayr) in the face of global climate change. Proceedings of the Royal Society of London B 271:2527-2535.

Sánchez-Cordero, V., V. Cirelli, M. Munguia, and S. Sarkar. 2005a. Place prioritization for biodiversity 


\section{Peterson - Uses And ReQuirements of Ecological Niche Models}

representation using species' ecological niche modeling. Biodiversity Informatics 2:11-23.

Sánchez-Cordero, V., P. Illoldi-Rangel, M. Linaje, S. Sarkar, and A. T. Peterson. 2005b. Deforestation and extant distributions of Mexican endemic mammals. Biological Conservation 126:465-473.

Schadt, S., F. Knauer, P. Kaczensky, E. Revilla, T. Wiegand, and L. Trepl. 2002. Rule-based assessment of suitable habitat and patch connectivity for the Eurasian lynx. Ecological Applications 12:1469-1483.

Scott, J. K., and F. D. Panetta. 1993. Predicting the Australian weed status of southern African plants. Journal of Biogeography 20:87-93.

Sindel, B. M., and P. W. Michael. 1992. Spread and potential distribution of Senecio madagascariensis pior (Fireweed) in Australia. Australian Journal of Ecology 17:21-26.

Skidmore, A. K., A. Gauld, and P. Walker. 1996. Classification of kangaroo habitat distribution using three GIS models. International Journal of Geographical Information Systems 10:441-454.

Skov, F. 2000. Potential plant distribution mapping based on climatic similarity. Taxon 49:503-515.

Soberón, J., and A. T. Peterson. 2004. Biodiversity informatics: Managing and applying primary biodiversity data. Philosophical Transactions of the Royal Society of London B 359:689-698.

Soberón, J., and A. T. Peterson. 2005. Interpretation of models of fundamental ecological niches and species' distributional areas. Biodiversity Informatics 2:1-10.

South, A., S. Rushton, and D. Macdonald. 2000. Simulating the proposed reintroduction of the European beaver (Castor fiber) to Scotland. Biological Conservation 93:103-116.

South, A. B., S. P. Rushton, D. W. Macdonald, and R. Fuller. 2001. Reintroduction of the European beaver (Castor fiber) to Norfolk, UK: a preliminary modelling analysis. Journal of Zoology 254:473-479.

Southgate, R., and H. Possingham. 1995. Modeling the reintroduction of the Greater Bilby Macrotis lagotis: Using the metapopulation model analysis of the likelihood of extinction (Alex). Biological Conservation 73:151-160.

Sutherst, R. W., G. F. Maywald, T. Yonow, and P. M. Stevens. 1999. CLIMEX User Guide--Predicting the Effects of Climate on Plants and Animals. CSIRO Publishing, Collingwood, Victoria, Australia.

Svenning, J.-C., and F. Skov. 2004. Limited filling of the potential range in European tree species. Ecology Letters 7:565-573.

Sykes, M. T., I. C. Prentice, and W. Cramer. 1996. A bioclimatic model for the potential distributions of north European tree species under present and future climates. Journal of Biogeography 23:203-233.

Thuiller, W., M. B. Araújo, and S. Lavorel. 2004. Do we need land-cover data to model species distributions in Europe? Journal of Biogeography 31:353-361.

Thuiller, W., S. Lavorel, M. B. Araújo, M. T. Sykes, and I. C. Prentice. 2005a. Climate change threats to plant diversity in Europe. Proceedings of the National Academy of Sciences USA 102:8245-8250.

Thuiller, W., G. F. Midgely, G. O. Hughes, B. Bomhard, G. Drew, M. C. Rutherford, and F. I. Woodward. 2006. Endemic species and ecosystem sensitivity to climate change in Namibia. Global Change Biology 12:759-776.

Thuiller, W., D. M. Richardson, P. Pysek, G. F. Midgely, G. O. Hughes, and M. Rouget. 2005b. Global risk assessment for plant invasions--The role of climatic suitability and propagule pressure. Global Change Biology 11:2234-2259.

Welk, E., K. Schubert, and M. H. Hoffmann. 2002. Present and potential distribution of invasive garlic mustard (Alliaria petiolata) in North America. Diversity and Distributions 8:219-233.

Wiens, J. J., and C. H. Graham. 2005. Niche conservatism: Integrating evolution, ecology, and conservation biology. Annual Review of Ecology and Systematics 36:519-539.

Williams, P., D. Gibbons, C. R. Margules, A. Rebelo, C. Humphries, and R. Pressey. 1996. A comparison of richness hotspots, rarity hotspots, and complementary areas for conserving diversity of British birds. Conservation Biology 10:155-174.

Williams, P. H., and M. B. Araújo. 2002. Apples, oranges, and probabilities: Integrating multiple factors into biodiversity conservation with consistency. Environmental Modeling and Assessment 7:139-151.

Williams, P. H., L. Hannah, S. Andelman, G. F. Midgely, M. B. Araújo, G. O. Hughes, L. L. Manne, E. Martínez-Meyer, and R. G. Pearson. 2005. Planning for climate change: Identifying minimumdispersal corridors for the Cape Proteaceae. Conservation Biology 19:1063-1074.

Wilson, K. A., M. I. Westphal, H. P. Possingham, and J. Elith. 2005. Sensitivity of conservation planning to different approaches to using predicted species distribution data. Biological Conservation 122:99112.

Zalba, S. M., M. I. Sonaglioni, and C. J. Belenguer. 2000. Using a habitat model to assess the risk of invasion by an exotic plant. Biological Conservation 93:203-208. 